OPEN ACCESS

Paper-Based Disk-Type Self-Powered Glucose Biosensor Based on Screen-Printed Biofuel Cell Array

To cite this article: Isao Shitanda et al 2019 J. Electrochem. Soc. 166 B1063

View the article online for updates and enhancements. 


\title{
Paper-Based Disk-Type Self-Powered Glucose Biosensor Based on Screen-Printed Biofuel Cell Array
}

\author{
Isao Shitanda, $\mathbb{1}^{1,2,=, *, z}$ Yuki Fujimura, ${ }^{1,=, * *}$ Saki Nohara, ${ }^{1}$ Yoshinao Hoshi, ${ }^{1}$ \\ Masayuki Itagaki, ${ }^{1,2, *}$ and Seiya Tsujimura ${ }^{2,3}$ \\ ${ }^{1}$ Department of Pure and Applied Chemistry, Faculty of Science and Technology, Tokyo University of Science, Noda, \\ Chiba 278-8510, Japan \\ ${ }^{2}$ Research Institute for Science and Technology, Tokyo University of Science, Noda, Chiba 278-8510, Japan \\ ${ }^{3}$ Division of Material Science, Faculty of Pure and Applied Science, University of Tsukuba, Tsukuba, Ibaraki \\ 305-5358, Japan
}

\begin{abstract}
There is an increasing need for wearable diagnostic sensor devices and for enzymatic biofuel cells (EBFCs) as efficient power sources. In this study, a six-glucose $/ \mathrm{O}_{2}$ biofuel cell array connected in series was fabricated by screen printing as a self-powered glucose sensor exhibiting an electromotive force of 3.2 V. Porous carbon electrodes were formed by screen printing of MgO-templated carbon on water-repellent paper to improve the performance of the cathode and thus prevent it from being the limiting step. The bioanode contained glucose oxidase as a catalyst and tetrathiafulvalene as a mediator, and the cathode contained bilirubin oxidase as an oxygen reduction catalyst. A good linear relationship was obtained between the output of EBFCs and glucose concentration (1-25 mM), which contains the range of urine glucose levels. The artificial urine components did not interfere with the output of the EBFC, but it was limited by low ion conductivity and low buffer capacity.

(C) The Author(s) 2019. Published by ECS. This is an open access article distributed under the terms of the Creative Commons Attribution 4.0 License (CC BY, http://creativecommons.org/licenses/by/4.0/), which permits unrestricted reuse of the work in any medium, provided the original work is properly cited. [DOI: $10.1149 / 2.1501912 \mathrm{jes}]$

(cc) BY
\end{abstract}

Manuscript submitted April 26, 2019; revised manuscript received July 26, 2019. Published August 5, 2019.

Considerable attention has been focused on the development of non-invasive wearable electrochemical biosensors that can diagnose health conditions using physiological fluids other than blood as analyte, such as saliva, sweat, tears, and urine. ${ }^{1-5}$ These fluids are readily available and do not require invasive procedures. Epidermal contact lens-type, and textile sensors have been developed. However, a power source is necessary for their continuous operation, and therefore, various energy harvesters (light, vibration, temperature difference) were developed. ${ }^{6-11}$ On the other hand, enzymatic biofuel cells (EBFCs) are a promising technology for wearable power sources, because they can generate electricity under conditions of normal temperature, normal pressure, and neutral $\mathrm{pH}$, and exhibit high biocompatibility and low environmental loading. ${ }^{12-20}$ EBFCs cannot only be a power source, but work as sensors themselves when their output depends on the concentration of the biomarker. ${ }^{21-24}$ Moreover, it is possible to construct a very simple wearable sensor that consumes less power because it does not require additional energy for operating the potentiostat for amperometry. One of the major challenges associated with the use of physiological fluids other than blood, is, however, the lower concentration of target analyte compared to blood. ${ }^{1}$ For example, the concentration of glucose in saliva and tears is up to 20-fold lower than in the blood. In contrast, glucose levels in urine are known to correlate with blood glucose levels ${ }^{25,26}$ and are high compared to saliva or tears. Urinary glucose is detected when the blood glucose level exceeds the kidneys' threshold $(\geq 10 \mathrm{mM})$, and glucose concentration in the urine is higher than $2.5 \mathrm{mM}$ for diabetic patients, which is sufficient to power electronic circuits. Detecting changes in urinary glucose level is important in diabetes monitoring, treatment, and prevention. Our final goal is the development of a wearable self-powered device that generates electricity when the urine contains glucose and wirelessly communicates the information using the generated electricity. The sensor will be installed in diapers to collect urine. This urine glucose sensor will be required to have the following characteristics; flexibility, light weight, disposability, rapid startup, and power (voltage of $3 \mathrm{~V}$ ). Wireless communication tools such as Bluetooth Low Energy are designed for operation using a Li-battery that requires $3 \mathrm{~V}$ of operational voltage. ${ }^{27}$

Our group has developed paper-based glucose $/ \mathrm{O}_{2}$ BFCs based on screen printing technology. ${ }^{28}$ Paper is a cheap, lightweight, and

\footnotetext{
$=$ These authors contributed equally to this work

*Electrochemical Society Member.

**Electrochemical Society Student Member.

zE-mail: shitanda@rs.noda.tus.ac.jp
}

biodegradable substrate for use in wearable EBFCs that can be incorporated in a diaper. Further, liquid can infiltrate hydrophilic cellulose fibers in paper without requiring an active pump and move by capillary action without requiring an external supply source or modified chemical substance. We also developed porous electrode materials suitable for application in enzymatic electrodes for improvement of the output power of EBFCs. ${ }^{29}$ A single cell has an open circuit voltage of $0.6 \mathrm{~V}$, and the cell voltage can be improved by increasing the number of cells connected in series. ${ }^{30-32}$ It is possible to control the output power according to the target device by designing an array system. In this study, we designed a BFC type sensor based on our previous work $^{31}$ in which BFCs are arranged in series in a circle with the following modifications. The total cell voltage is boosted to more than $3 \mathrm{~V}$ by increasing the number of cells from 5 to 6 for achievement of wireless communication in near future. The total output power was limited by the anodic current depending on glucose concentration. The cathodic performance was improved by using pore size-controlled $\mathrm{MgO}$-templated carbon. ${ }^{33}$ We also designed a configuration BFC in which liquid can be delivered to the entire cell even when only a small amount of urine is used. Finally, we tested the effects of urine components on the performance and stability of the devices using artificial urine.

\section{Experimental}

Materials._Glucose oxidase (GOx, from Aspergillus niger, $100 \mathrm{U} / \mathrm{mg}$ ) and tetrathiafulvalene (TTF) were purchased from SigmaAldrich (Japan). TTF was dissolved in methanol solution. Myrothecium verrucaria bilirubin oxidase (BOD) was purchased from Amano enzyme (BO"Amano3", Japan). MgO-templated carbon (MgOC) particles (100 nm pore size, $\mathrm{MJ}(3) 100)$ were kindly provided by Toyo Tanso (Japan). Poly(vinylidenedifluoride) (PVdF, 5\% in N-methylpyrrolidone (NMP), \#9305, Kureha, Japan) was used. Artificial urine was purchased from Isekyu (Japan), with the following composition: urea $25 \mathrm{~g}(420 \mathrm{mM}), \mathrm{NaCl} 9 \mathrm{~g}(150 \mathrm{mM}), \mathrm{KH}_{2} \mathrm{PO}_{4} 2.5 \mathrm{~g}$ (20 mM), Na $\mathrm{HPO}_{4} 2.5 \mathrm{~g}(20 \mathrm{mM}), \mathrm{NH}_{4} \mathrm{Cl} 3 \mathrm{~g}(55 \mathrm{mM})$, creatinine $2 \mathrm{~g}(18 \mathrm{mM})$, and $\mathrm{Na}_{2} \mathrm{SO}_{3} 3 \mathrm{~g}(24 \mathrm{mM})$ dissolved in $1 \mathrm{~L}$ of distilled water.

Fabrication of electrodes.-Filter paper (Whatman No. 1002-110) was used as the substrate. First, current collectors with a width of $10 \mathrm{~mm}$ and a length of $20 \mathrm{~mm}$ were printed on a filter paper using carbon paste (JELCON CH-10, Jujo Chemicals, Japan) with a 
(a) Printing conductive carbon layer

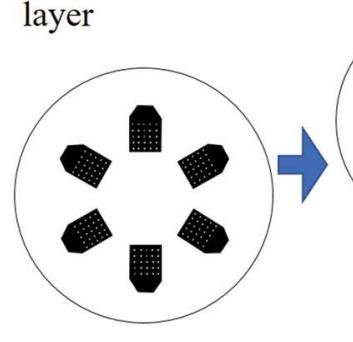

(d) Printing porous carbon layer

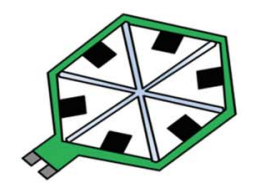

(b) Printing silver layer
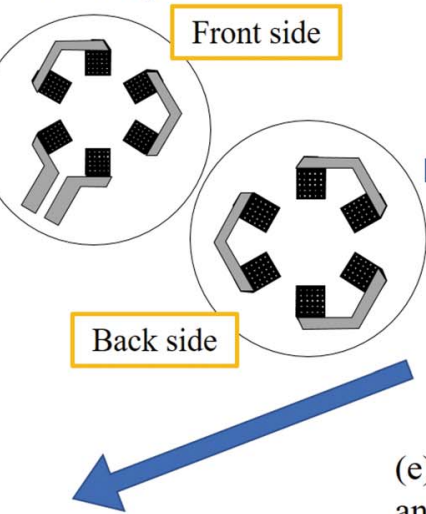

(e) Constructing bioanode and biocathode (c) Printing resist layer

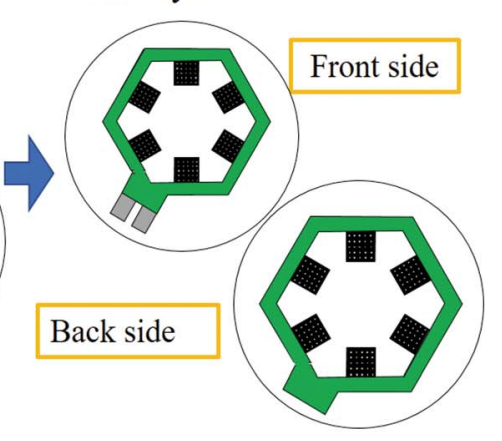

\section{and biocathode}

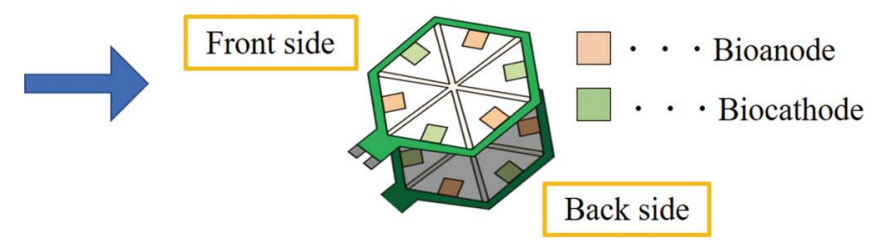

Figure 1. Schematic representation of the design and fabrication of the printed, enzymatic cell array.

screen printer (LS-150 TV, New Long Precision Industry, Japan). The printing of current collector layer was repeated four times to decrease the resistance to as low as $40 \mathrm{ohms}$. After drying for $30 \mathrm{~min}$ at $120^{\circ} \mathrm{C}$ in an electric oven, the overleaf was subjected to water repellent treatment using a water repellent, Fluorosurf FG 3030 C-30 (Fluoro Technology, Japan) in order to prevent a short circuit. Subsequently, porous carbon was printed on the current collector $\left(10 \times 10 \mathrm{~mm}^{2}\right)$ as the enzyme reaction region, followed by drying at $60^{\circ} \mathrm{C}$ for 1 day. The current collector contains 25 holes (each $1 \mathrm{~mm}$ in diameter) for supplying the electrolytic solution to the porous carbon layer. The porous carbon ink was prepared by kneading $2 \mathrm{~g}$ of $\mathrm{MgOC}, 10 \mathrm{~mL}$ of PVdF as a binder, and $5 \mathrm{~mL}$ of NMP as a solvent at $2000 \mathrm{rpm}$ for $1 \mathrm{~min}$, using a rotation revolution mixer ARE-310 (Thinky, Japan). The printed porous carbon electrode was then treated with UV ozone for $15 \mathrm{~min}$ for enzyme loading.

For the GOx-anode, $20 \mu \mathrm{L}$ of the mediator, TTF, saturated in methanol was applied on the electrode and after drying for $15 \mathrm{~min}$ under reduced pressure, GOx $(20 \mathrm{U} / \mu \mathrm{L})$ dissolved in $10 \mathrm{mM}$ phosphate buffer solution ( $\mathrm{pH} 7.0$ ), containing $0.01 \%$ surfactant Triton $\mathrm{X}-100$ (Roche Diagnostics $\mathrm{GmbH}$ ), was applied and the anode was dried under reduced pressure for $1 \mathrm{~h}$.

For the BOD-biocathode, an aliquot of BOD $(1 \mathrm{U} / \mu \mathrm{L})$ dissolved in $10 \mathrm{mM}$ phosphate buffer solution ( $\mathrm{pH} 7.0$ ), containing $0.01 \%$ Triton $\mathrm{X}-100$, was applied on the electrode, followed by drying under reduced pressure for $1 \mathrm{~h}$ to obtain a biocathode. The glucose biofuel cell (single cell) was prepared by bonding the bioanode and biocathode as described previously. ${ }^{31}$

Fabrication of the printed EBFC array.-A disk type biofuel cell array with a diameter of $70 \mathrm{~mm}$, in which six cells are connected in series, was fabricated as shown in Fig. 1. The printed EBFC was prepared by pasting the bioanode and biocathode sheets as shown in panels (d) and (e) in Figure 1. First, carbon paste was printed on the filter paper as the current collector and dried at $120^{\circ} \mathrm{C}$ for $30 \mathrm{~min}$. This process was repeated five times to increase the electric conductivity and then, each cell was connected by printing a silver line (ECM-100 AF 5000, Taiyo Ink, Japan), followed by drying at $120^{\circ} \mathrm{C}$ for $30 \mathrm{~min}$. After repeating this process twice, a water resistant layer was printed. The water resistant ink was prepared by mixing the main agent (DSR-330T1211, Tamura Seisakusho, Japan) with a curing agent (CA-330T12-11,
Tamura Seisakusho, Japan) at a ratio of 7:3 and the film was dried at $120^{\circ} \mathrm{C}$. Subsequently, the porous carbon ink was printed and dried at $60^{\circ} \mathrm{C}$. Porous carbon layers were printed three times to increase the thickness. Thereafter, the compartment was separated to prevent a short circuit by printing a gap, using water repellent ink Fluorosurf FG 3030 C-30. For the anode electrode, TTF and GOx were applied on the electrode, and for the cathode, BOD was applied on the cathode. The anode and cathode were attached in such a way as to ensure that the printed surface was exposed to the outside. The bioanode and biocathode were alternately printed, such that a disk type biofuel cell array, in which six cells were connected in series, was obtained when they were stacked together. The cross sectional view of the disk type biofuel cell array was shown in Fig. S1.

Electrochemical measurement.-The performance of the GOx-modified anode and BOD-modified cathode were analyzed separately by a three-electrode system using a potentiostat (IVIUM Compact stat) with an $\mathrm{Ag} \mid \mathrm{AgCl}$ reference and a platinum counter electrode. The electrodes were dipped in phosphate buffer $(\mathrm{pH} 7.0)$ containing 0-100 mM glucose. The performance of the printed EBFC was analyzed by liner sweep voltammetry with a two-electrode system using a potentiostat by applying either phosphate buffer or artificial urine containing glucose. All electrochemical measurements were carried out at $37^{\circ} \mathrm{C}$. The current density and power density were calculated based on the projected surface area of the electrodes used. All measurements were performed three times. Error bars were determined using the Student $t$ distribution at a $68.3 \%$ confidence level $(\mathrm{n}=3)$.

\section{Results and Discussion}

Dependence of biocathode performance on enzyme loading.Figure 2A shows the cyclic voltammograms (CVs) of BOD-cathode depending on the amount of $\operatorname{BOD}(0,5,10,15,20,30$, or $40 \mathrm{U}$ per $1 \mathrm{~cm}^{-2}$ of electrode) at the scan rate of $10 \mathrm{mVs}^{-1}$ in $1 \mathrm{M}$ phosphate buffer ( $\mathrm{pH} 7.0$ ). In the absence of BOD, no oxygen reduction current was observed in this potential range. However, in the presence of BOD, clear catalytic current was observed. Maximum oxygen reduction current density $\left(-2.9 \mathrm{~mA} \mathrm{~cm}^{-2}\right.$ at $\left.-0.2 \mathrm{~V}\right)$ was observed at $5 \mathrm{U} \mathrm{cm}^{-2} \mathrm{BOD}$ loaded on the electrode surface; catalytic current 

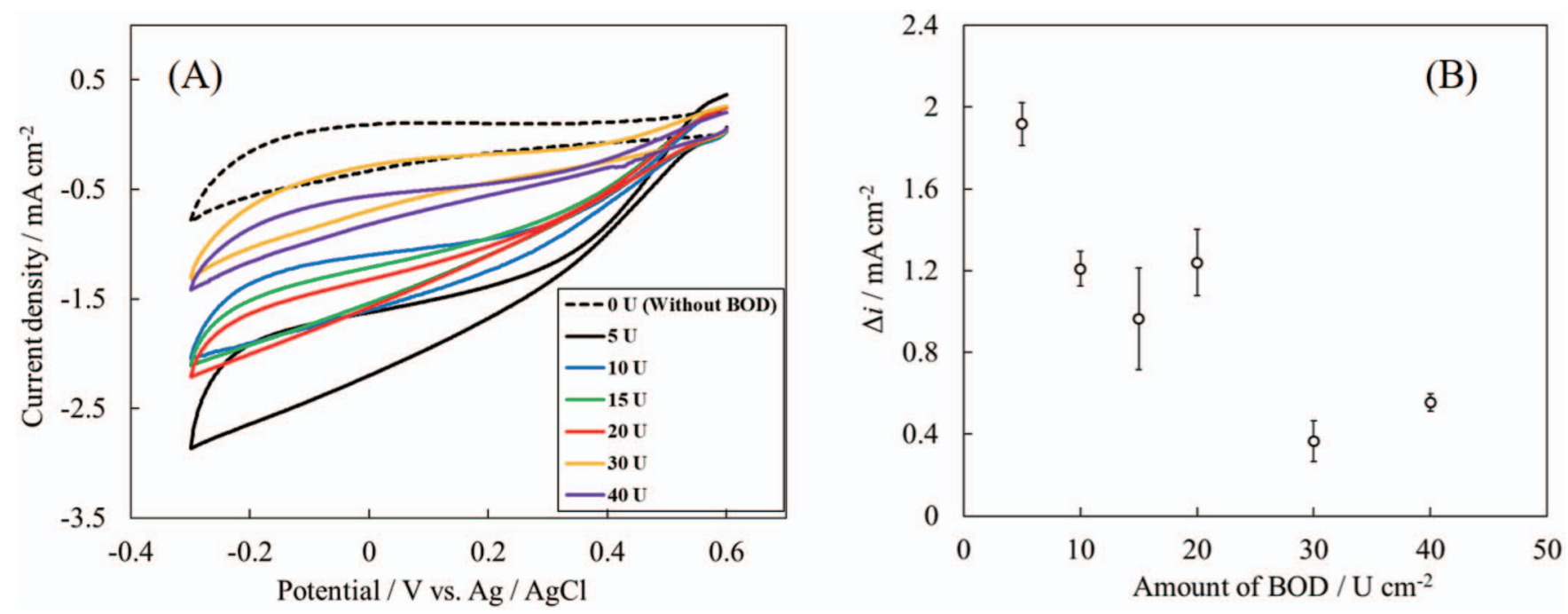

Figure 2. (A) Cyclic voltammograms of bilirubin oxidase (BOD) biocathode at $10 \mathrm{mVs}^{-1}$ in $1 \mathrm{M}$ phosphate buffer, $\mathrm{pH} 7.0$, under air-saturated conditions at different BOD loadings. (B) Dependence of catalytic current at $-0.3 \mathrm{~V}$ on the amount of BOD.

decreased as the amount of BOD increased. The catalytic current density of this BOD-cathode was approximately 4 times larger than that of a BOD-cathode prepared in our previously work, ${ }^{28}$ in which Ketjen black was used as porous carbon material. By using the $\mathrm{MgOC}$ as the enzyme-immobilized material, the redox center of the BOD entrapped in the mesopore of $\mathrm{MgOC}$ can more effectively approach the electrode surface. ${ }^{34}$ Thus, the catalytic current density was found to be drastically improved.

Figure $2 \mathrm{~B}$ shows the catalytic current density at $-0.3 \mathrm{~V}$ plotted against BOD loading. Because the biocathode in this study is based on a direct electron-transfer type enzyme electrode reaction without a redox mediator, the catalytic current depends on the amount of the enzyme adsorbed on the electrode surface. ${ }^{28}$ The excess loading might fill the pores on the carbon and prevent the mass transfer of $\mathrm{O}_{2}$ to the enzyme on the electrode surface. Another possible explanation is the hydrophobic/hydrophilic characteristics of the carbon surface. The hydrophilicity of the electrode is important for ion conductivity and enzyme loading (penetration of enzyme solution into the carbon inner pose space); in contrast, the hydrophobicity of the carbon electrode is also important for the mass transfer of $\mathrm{O}_{2}$ through the carbon material. The excess loading of BOD could increase surface hydrophilicity, causing inhibition of oxygen diffusion on the surface around the BOD.

Dependence of anode performance on the amount of GOx and glucose concentration.-We studied the dependence of the glucose oxidation current generation on GOx loading. Different amounts of GOx were applied on the electrode $\left(10,50,100,250\right.$, or $\left.400 \mathrm{Ucm}^{-2}\right)$. Figure $3 \mathrm{~A}$ shows the $\mathrm{CVs}$ obtained at $10 \mathrm{mVs}^{-1}$ in phosphate buffer (pH 7.0) in the absence and presence of glucose $(100 \mathrm{mM})$. Whereas only charging current was observed in the absence of glucose, clear catalytic current for glucose oxidation was observed in the presence of glucose. The voltammogram did not show the typical sigmoidal curve, suggesting that the interfacial electron transfer kinetics is slow, compared to the enzymatic kinetics. At $0.3 \mathrm{~V}$, the magnitude of the catalytic current depended on the enzyme loading, but the dependence was not significant, and even at $10 \mathrm{Ucm}^{-2}$ of GOx, $4 \mathrm{mAcm}^{-2}$ of high glucose oxidation current was observed.

The dependence of the catalytic current on the enzyme loading indicates that only the enzyme at the vicinity of the electrode surface contributed to the current generation, via the mediation of TTF located near the electrode surface; therefore, the high enzyme loading does
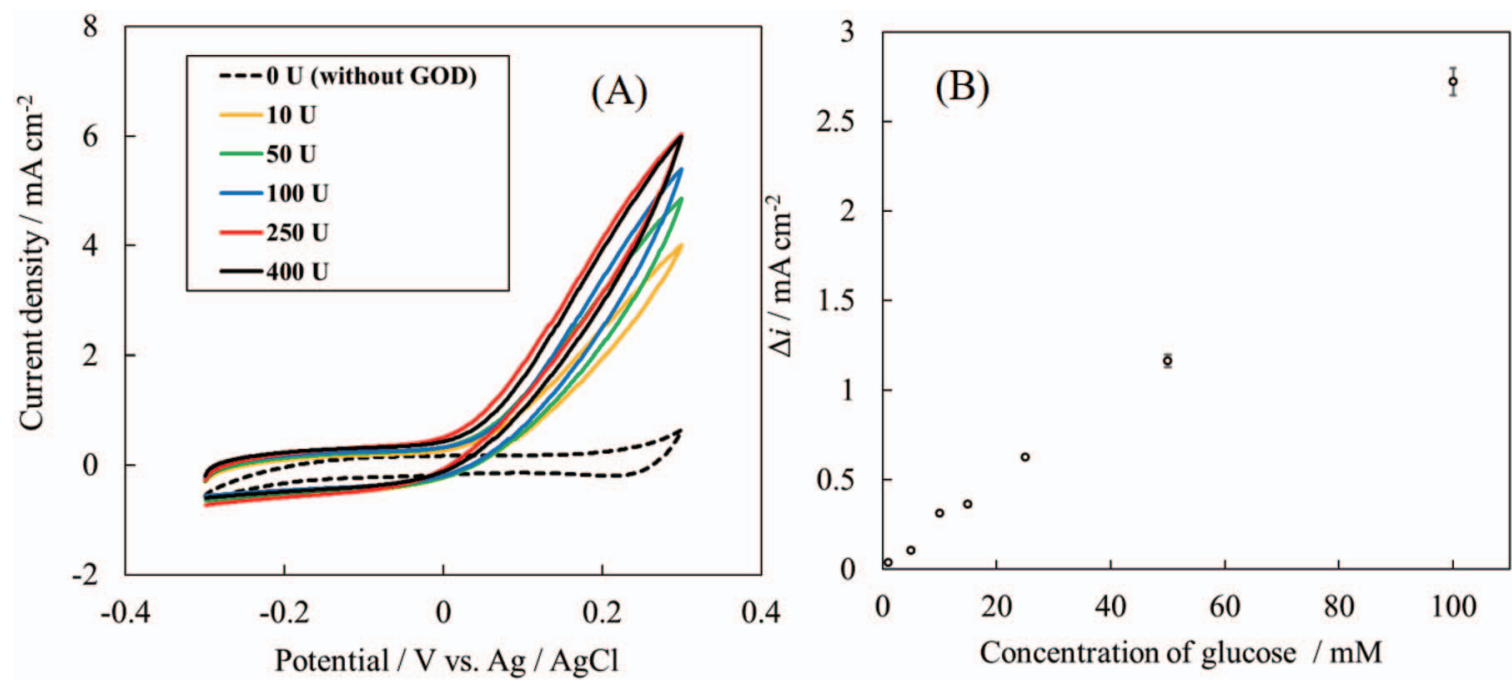

Figure 3. (A) Cyclic voltammograms of glucose oxidase (GOx) and tetrathiafulvalene (TTF) bioanodes at $10 \mathrm{mVs}^{-1}$ in $1 \mathrm{M}$ phosphate buffer, $\mathrm{pH} 7.0$, containing different amounts of GOx. (B) Dependence of glucose catalytic oxidation current at $0.3 \mathrm{~V}$ on the glucose concentration. 

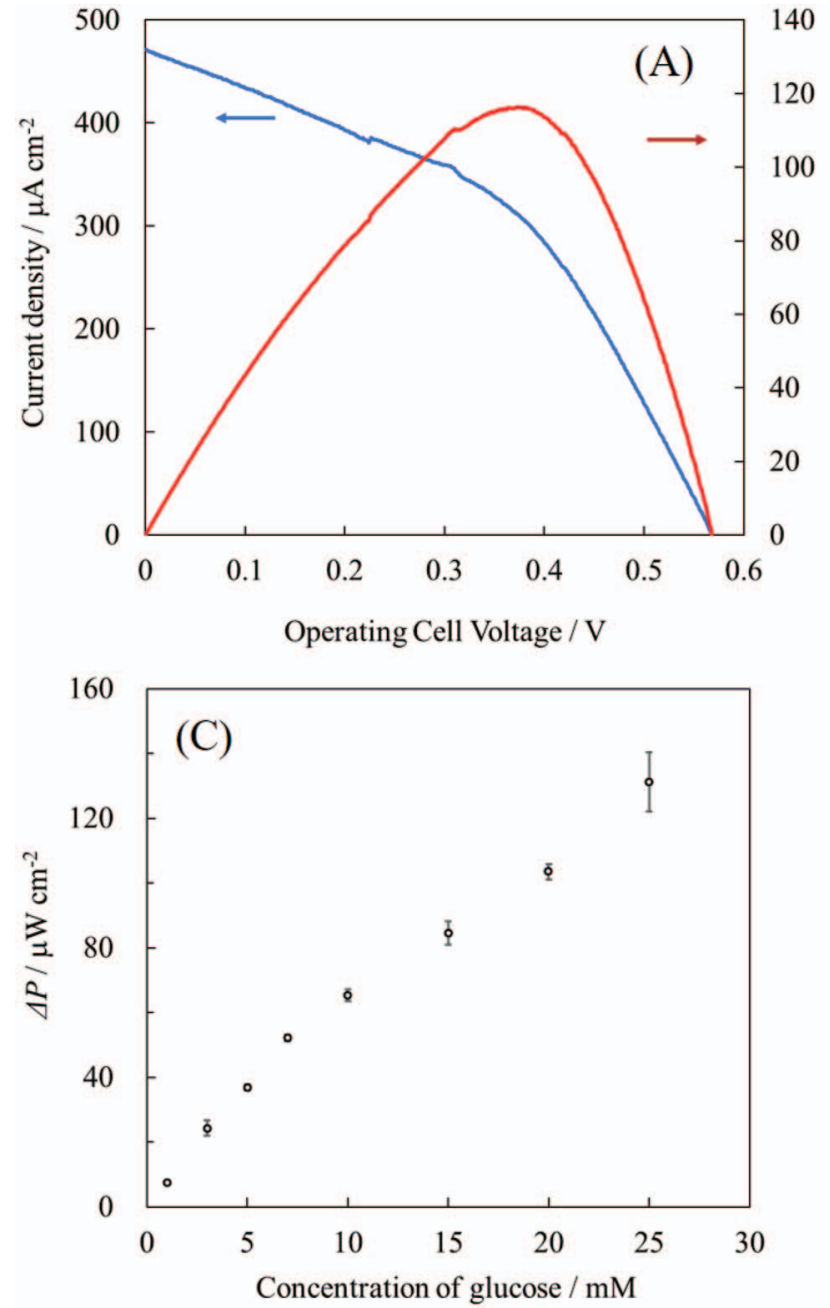

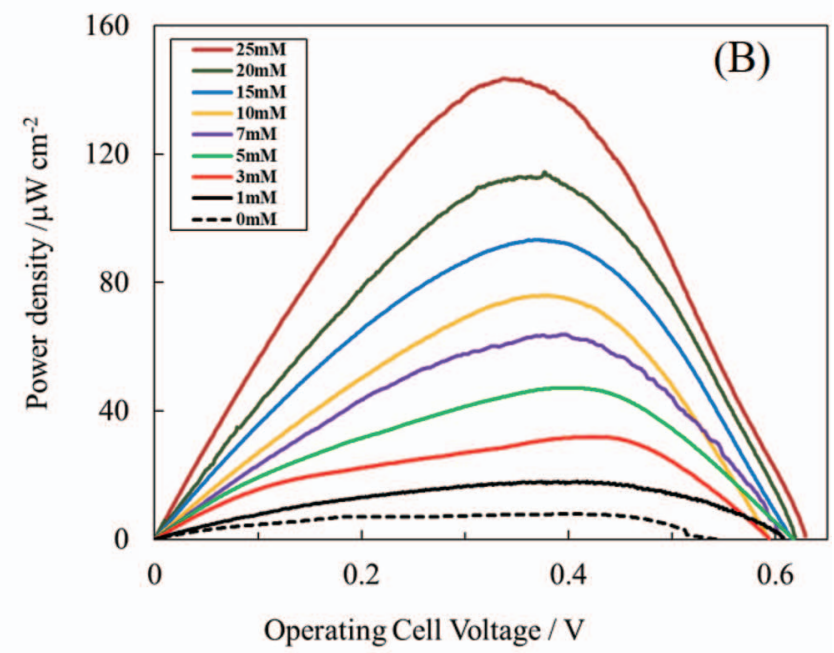

Operating Cell Voltage / V

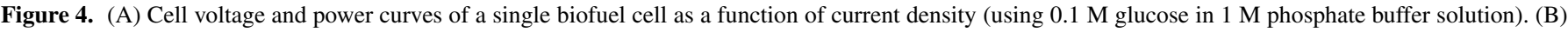
Dependence of the power-current curve on the concentration of glucose. (C) Maximum power plotted against glucose concentration.

not lead to high catalytic current. This result also suggests that, at high enzyme loading, the mass transfer of glucose and ions through the carbon layer was not disturbed by the enzyme adsorbed on the electrode surface, owing to the high specific surface area provided by MgOC. The controlled pore structure allowed smooth mass transfer when the pores were not filled with enzymes.

Figure $3 \mathrm{~B}$ shows the dependence of the anodic current for glucose oxidation on the glucose concentration. The amount of GOx was fixed at $400 \mathrm{Ucm}^{-2}$. The catalytic current after $600 \mathrm{~s}$ of constant potential electrolysis was plotted against the glucose concentration $(1,5,10,15$, $25,50$, and $100 \mathrm{mM}$ ) contained in $1 \mathrm{M}$ of phosphate buffer ( $\mathrm{pH} 7.0)$. Good linear response current was observed in this glucose concentration range. The maximum current at $100 \mathrm{mM}$ was $2.5 \mathrm{mAcm}^{-2}$, which was smaller than the cathodic current. Thus, when the biofuel cell is fabricated by combining the anode and cathode, the output power will depend on glucose concentration.

Evaluation of the performance of a single glucose EBFC.-The performance of the EBFC was evaluated by linear sweep voltammetry using the two-electrode method. Figure 4A shows the voltage-current curve of a single cell using $1 \mathrm{M}$ phosphate buffer ( $\mathrm{pH}$ 7.0) containing $100 \mathrm{mM}$ glucose as an electrolytic solution. Here, we utilized $1 \mathrm{M}$ phosphate buffer to evaluate cell configuration under a condition in which the ion conductivity is not a limiting factor and found that the electromotive force was $0.57 \mathrm{~V}$, the maximum current density was $0.47 \mathrm{mAcm}^{-2}$, and the maximum power density was $0.12 \mathrm{mWcm}^{-2}$. Figure $4 \mathrm{~B}$ shows the voltage-current and power curves of a single cell at different glucose concentrations $(1,3,5,7,10,15,20$, and $25 \mathrm{mM})$. The maximum output power density increased linearly as the glucose concentration increased, as shown in the inset in Figure 4B. The open circuit potential did not depend on the concentration of glucose.

These results suggest that it may be possible to obtain output power depending on the concentration of glucose contained in the actual urine; thus, this system could be used as a self-driving sensor. The output power density at $5 \mathrm{mM}$ was $0.04 \mathrm{mWcm}^{-2}$, which is sufficient for the operation of small electric devices. ${ }^{27}$ However, it requires a booster to increase the operational voltage to drive an electric circuit, including light emitting diode (LED) and wireless communication tools. To power the electric devices without a booster, the EBFCs are usually stacked in series. The advantage of a printed EBFC is that it can be used to design an array structure as required.

\section{Evaluation of the performance of the glucose EBFC array.-} In our previous cell array design, the compartment was separated by cutting the paper. Thus, to operate the whole electrode, the glucose solution needed to be applied to each cell compartment. ${ }^{31}$ In this study, we devised a new design, wherein the EBFC was printed on one paper disk, without cutting into small compartments, which enabled the continuous supply of solution to each electrode arranged radially. As a result, the solution was supplied to the entire electrode after the application of urine only at a single point (i.e., the center of the cell array). Figure 5 shows the voltage-current and power curve of the cell array measured by linear sweep voltammetry at a scan rate of $1 \mathrm{mVs}^{-1}$, in $1 \mathrm{M}$ phosphate buffer ( $\mathrm{pH}$ 7.0) containing $100 \mathrm{mM}$ of glucose. The 


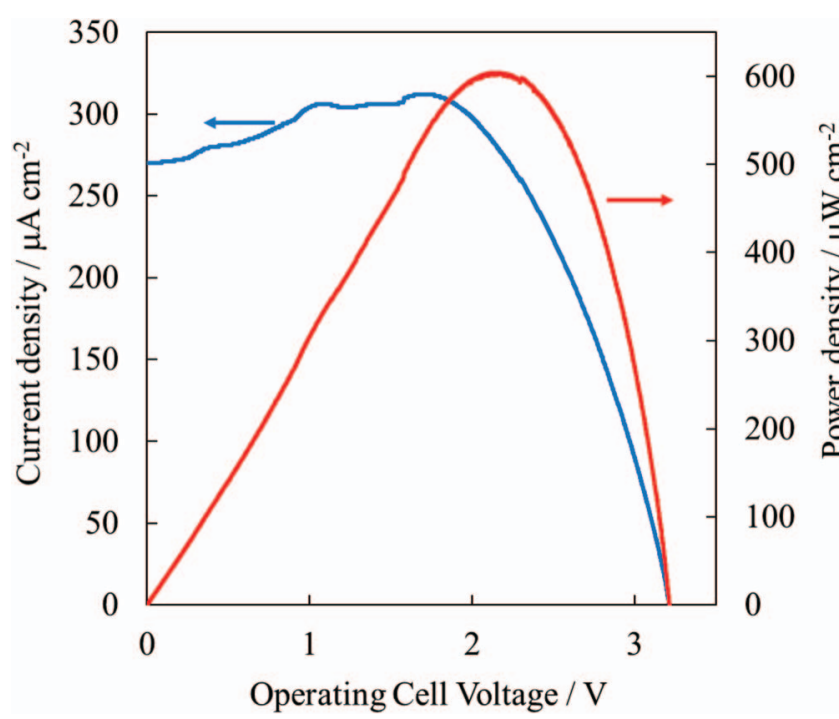

Figure 5. Cell voltage and power curves of the biofuel cell array as a function of current density (using $0.1 \mathrm{M}$ glucose in $1 \mathrm{M}$ phosphate buffer solution).

open circuit voltage was $3.2 \mathrm{~V}$ with a maximum output of $0.6 \mathrm{~mW}$ at $2.3 \mathrm{~V}$. It should be noted that the electricity generation was evokedimmediately after the application of urine to the center of the cell array. The electromotive force above $3 \mathrm{~V}$ can drive several electric circuits, the electric buzzer, and LED without a booster (Figure S2).

Electricity generation from glucose in artificial urine.-We investigated the influence of each component contained in artificial urine on the bioanode and biocathode activity. For bioanode, the catalytic current was measured in $1 \mathrm{M}$ phosphate buffer $(\mathrm{pH}$ 7.0) containing each component in artificial urine and voltammogram in each case was almost the same as that in the absence of any urine components (1 M phosphate buffer); thus, it can be safely concluded that these components did not inhibit the TTF-mediated GOx reaction. Similarly, we investigated the influence of each urine component on the BOD-biocathode activity and found that the voltammograms of the biocathode in $1 \mathrm{M}$ phosphate buffer ( $\mathrm{pH}$ 7.0) containing each component in artificial urine, except for the $150 \mathrm{mM} \mathrm{NaCl}$, were similar to that in the case of $1 \mathrm{M}$ phosphate buffer alone. The oxygen reduction current density at $0 \mathrm{~V}$ of the biocathode in $1 \mathrm{M}$ phosphate buffer $(\mathrm{pH}$ 7.0) containing $150 \mathrm{mM} \mathrm{NaCl}$ was $82 \%$ that in $1 \mathrm{M}$ phosphate buffer alone, and the onset potential was shifted by $0.1 \mathrm{~V}$ in the negative direction. Chloride ions are well known to inhibit the activity of $\mathrm{BOD},{ }^{35}$ but other components did not influence BOD activity.

Subsequently, the performance of the anode and cathode was evaluated using artificial urine. In comparison with the performance in $1 \mathrm{M}$ phosphate buffer solution, both the anode and cathode showed lower catalytic current density, $73 \%$ for the anode and $62 \%$ for the cathode as compared to those in $1 \mathrm{M}$ phosphate buffer (Figure 6A). The decrease can be explained by the local pH change around enzyme and low ion conductivity. At the bioanode, protons are formed when glucose is oxidized to glucono-lactone by GOx and at the biocathode, oxygen and protons are converted to water by BOD. Thus, the low buffer concentration, i.e., the low buffer capacity, leads to local $\mathrm{pH}$ change in the porous carbon during the electro-chemical enzymatic reaction. To confirm this, we studied the performance of the bioelectrodes in $20 \mathrm{mM}$ phosphate buffer, which has the same phosphate concentration as artificial urine. For the anode, the current in the $20 \mathrm{mM}$ phosphate buffer (59\% of the current in $1 \mathrm{M}$ phosphate buffer) was lower than that in the artificial urine, because the ion conductivity is lower. For the cathode, the current in $20 \mathrm{mM}$ phosphate buffer $(70 \%$ of the current in $1 \mathrm{M}$ phosphate buffer) was higher than in the artificial urine, where BOD activity could be inhibited by the chloride ions.
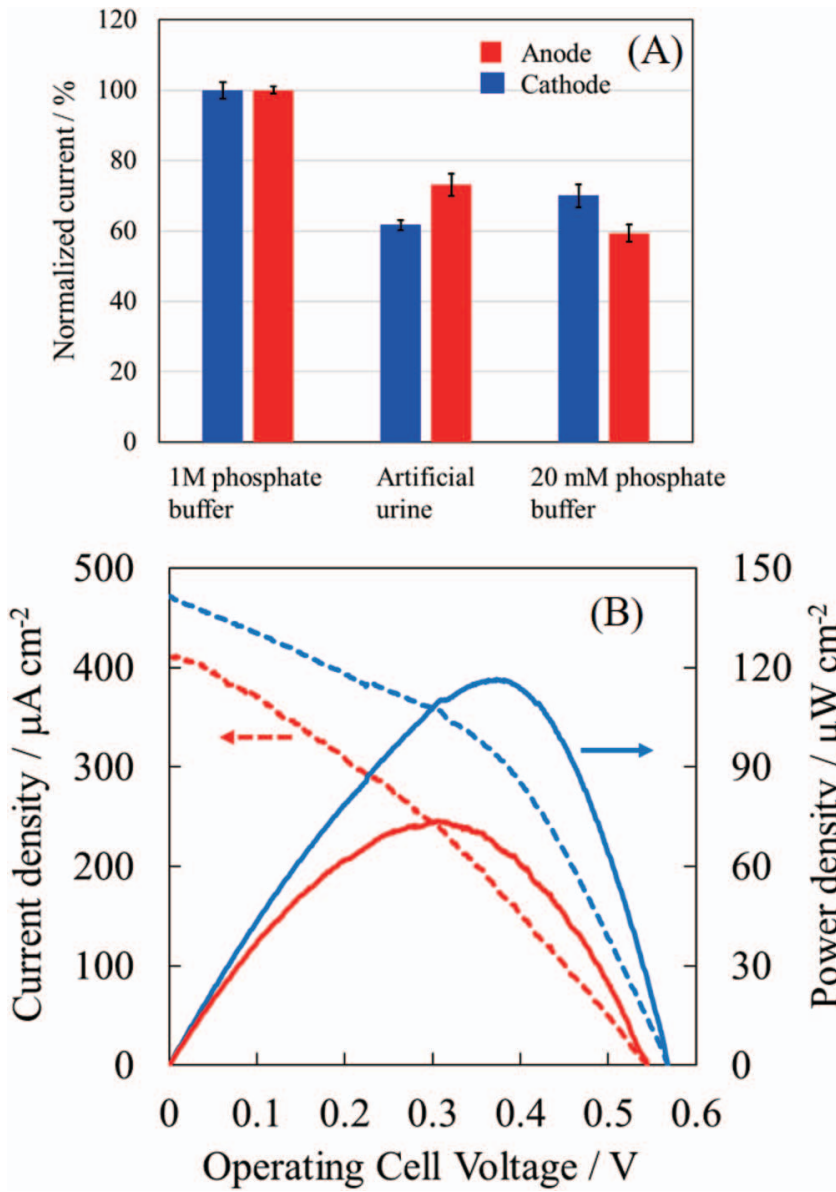

Figure 6. (A) Comparison of anode and cathode performance evaluated in $1 \mathrm{M}$ phosphate buffer solution, $20 \mathrm{mM}$ phosphate buffer solution, and artificial urine. (B) Cell voltage and power curves of the printed single enzymatic biofuel cell (EBFC) as a function of current density in $1 \mathrm{M}$ phosphate buffer (blue line) and in artificial urine (red line).

Finally, we compared the performance of the printed EBFC in $1 \mathrm{M}$ phosphate buffer and in artificial urine (Figure 6B). The open circuit potential was $0.55 \mathrm{~V}$, which is $0.1 \mathrm{~V}$ lower than that in $1 \mathrm{M}$ phosphate buffer. The maximum power density was $0.07 \mathrm{~mW} \mathrm{~cm}^{-2}$, which is in agreement with the expected value from the voltammetric study described above. The low ionic conductivity can be overcome by optimizing the electrode configuration, size, and shape and by reducing the distance between the anode and cathode.

\section{Conclusions}

A glucose $/ \mathrm{O}_{2}$ EBFC-type glucose sensor printed on a paper substrate was successfully fabricated. The open circuit voltage of the EBFC, in which a six-biofuel cell array was connected in series, was $3.2 \mathrm{~V}$. To utilize it as a diagnostic device for diabetes, we confirmed the dependence of the output power on glucose concentration in the range of 1-25 $\mathrm{mM}$ using $\mathrm{MgO}$-template carbon to improve the cathodic electroenzymatic reaction and the mass transfer of fuel through the carbon material. No component of the artificial urine interfered with the self-powered biosensor response. The proposed self-powered glucose sensor does not need batteries or other power sources and is expected not only to be a urinary glucose level monitoring tool in diabetic patient care (especially for people needing nursing care) in the future, but also to be a new diaper accessory capable of detecting urine if glucose is embedded in the BFC. 


\section{Acknowledgments}

This work was partially supported by JST-ASTEP grant Number JPMJTS1513, JSPS grant Number 17H02162, and Private University Research Branding Project (2017-2021) from the Ministry of Education, Culture, Sports, Science and Technology.

\section{ORCID}

Isao Shitanda (1D https://orcid.org/0000-0001-9751-016X

Yoshinao Hoshi (D) https://orcid.org/0000-0002-4179-7939

\section{References}

1. C. Gonzalez-Solino and M. D. Lorenzo, Biosensors (Basel), 8 (2018).

2. W. Gao, S. Emaminejad, H. Y. Nyein, S. Challa, K. Chen, A. Peck, H. M. Fahad, H. Ota, H. Shiraki, D. Kiriya, D. H. Lien, G. A. Brooks, R. W. Davis, and A. Javey, Nature, 529, 509 (2016).

3. J. Kim, A. S. Campbell, and J. Wang, Talanta, 177, 163 (2018).

4. S. Imani, A. J. Bandodkar, A. M. Mohan, R. Kumar, S. Yu, J. Wang, and P. P. Mercier, Nature communications, 7, 11650 (2016).

5. J. Kim, A. S. Campbell, B. E.-F. de Ávila, and J. Wang, Nature Biotechnology, 37, 389 (2019).

6. G. J. Hedley, A. Ruseckas, and I. D. W. Samuel, Chemical Reviews, 117, 796 (2017)

7. B. Russ, A. Glaudell, J. J. Urban, M. L. Chabinyc, and R. A. Segalman, Nature Reviews Materials, 1 (2016).

8. F. R. Fan, W. Tang, and Z. L. Wang, Adv. Mater, 28, 4283 (2016).

9. A. Abdelkefi, International Journal of Engineering Science, 100, 112 (2016).

10. Z. L. Wang, J. Chen, and L. Lin, Energy \& Environmental Science, 8, 2250 (2015).

11. Z. Wang, X. M. Pan, Y. H. He, Y. M. Hu, H. S. Gu, and Y. Wang, Advances in Materials Science and Engineering (2015).

12. A. Heller, Physical Chemistry Chemical Physics, 6, 209 (2004).

13. R. A. Bullen, T. C. Arnot, J. B. Lakeman, and F. C. Walsh, Biosens Bioelectron, 21, 2015 (2006).

14. S. C. Barton, J. Gallaway, and P. Atanassov, Chemical Reviews, 104, 4867 (2004)
15. A. J. Gross, M. Holzinger, and S. Cosnier, Energy \& Environmental Science, 11, 1670 (2018).

16. S. Sahin, R. Cai, R. D. Milton, S. Abdellaoui, F. C. Macazo, and S. D. Minteer, Journal of the Electrochemical Society, 165, H109 (2018).

17. J. H. Franco, S. D. Minteer, and A. R. de Andrade, Journal of the Electrochemical Society, 165, H575 (2018).

18. Y. C. Hui, X. Y. Ma, F. J. Qu, F. Chen, and Y. Chen, Journal of the Electrochemical Society, 164, G112 (2017).

19. Y. Holade, S. Tingry, K. Servat, T. W. Napporn, D. Cornu, and K. B. Kokoh, Catalysts, 7 (2017).

20. A. B. Engel, Y. Holade, D. Cornu, K. Servat, T. W. Napporn, K. B. Kokoh, and S. Tingry, Journal of the Electrochemical Society, 164, G29 (2017).

21. A. J. Bandodkar and J. Wang, Electroanalysis, 28, 1188 (2016).

22. M. Zhou, Electroanalysis, 27, 1786 (2015).

23. K. Sode, T. Yamazaki, I. Lee, T. Hanashi, and W. Tsugawa, Biosensors \& Bioelectronics, 76, 20 (2016).

24. G. Valdes-Ramirez, Y.-C. Li, J. Kim, W. Jia, A. J. Bandodkar, R. Nunez-Flores, P. R. Miller, S.-Y. Wu, R. Narayan, J. R. Windmiller, R. Polsky, and J. Wang, Electrochemistry Communications, 47, 58 (2014).

25. P. Sharma and P. Sharan, Ieee Sensors Journal, 15, 1035 (2015).

26. M. Miyashita, N. Ito, S. Ikeda, T. Murayama, K. Oguma, and J. Kimura, Biosensors \& Bioelectronics, 24, 1336 (2009).

27. M. Gamella, A. Koushanpour, and E. Katz, Bioelectrochemistry, 119, 33 (2018).

28. I. Shitanda, S. Kato, Y. Hoshi, M. Itagaki, and S. Tsujimura, Chemical Communications, 49, 11110 (2013).

29. S. Tsujimura, K. Murata, and W. Akatsuka, Journal of the American Chemical Society, 136, 14432 (2014).

30. I. Shitanda, S. Kato, S. Tsujimura, Y. Hoshi, and M. Itagaki, Chemistry Letters (2017).

31. I. Shitanda, S. Nohara, Y. Hoshi, M. Itagaki, and S. Tsujimura, Journal of Power Sources, 360, 516 (2017)

32. I. Shitanda, M. Momiyama, N. Watanabe, T. Tanaka, S. Tsujimura, Y. Hoshi, and M. Itagaki, ChemElectroChem (2017).

33. S. Tsujimura and K. Murata, Electrochimica Acta, 180, 555 (2015).

34. I. Shitanda, H. Nakafuji, S. Tsujimura, Y. Hoshi, and M. Itagaki, Electrochemistry, 83, 329 (2015).

35. A. de Poulpiquet, C. H. Kjaergaard, J. Rouhana, I. Mazurenko, P. Infossi, S. Gounel, R. Gadiou, M. T. Giudici-Orticoni, E. I. Solomon, N. Mano, and E. Lojou, ACS Catalysis, 7, 3916 (2017). 